\title{
Stimulating Interactive Apps in Conserving Batik Block Pattern
}

\section{Norfadilah Kamaruddin, Mohammad Shahir Ab Satar, Hafizah Rosli}

To Link this Article: http://dx.doi.org/10.6007/IJARBSS/v11-i10/10918 DOI:10.6007/IJARBSS/v11-i10/10918

Received: 08 August 2021, Revised: 13 September 2021, Accepted: 30 September 2021

Published Online: 11 October 2021

In-Text Citation: (Kamaruddin et al., 2021)

To Cite this Article: Kamaruddin, N., Satar, M. S. A., \& Rosli, H. (2021). Stimulating Interactive Apps in Conserving Batik Block Pattern. International Journal of Academic Research in Business and Social Sciences, 11(10), 426-432.

\section{Copyright: (c) 2021 The Author(s)}

Published by Human Resource Management Academic Research Society (www.hrmars.com) This article is published under the Creative Commons Attribution (CC BY 4.0) license. Anyone may reproduce, distribute, translate and create derivative works of this article (for both commercial and non-commercial purposes), subject to full attribution to the original publication and authors. The full terms of this license may be seen at: http://creativecommons.org/licences/by/4.0/legalcode

Full Terms \& Conditions of access and use can be found at http://hrmars.com/index.php/pages/detail/publication-ethics 


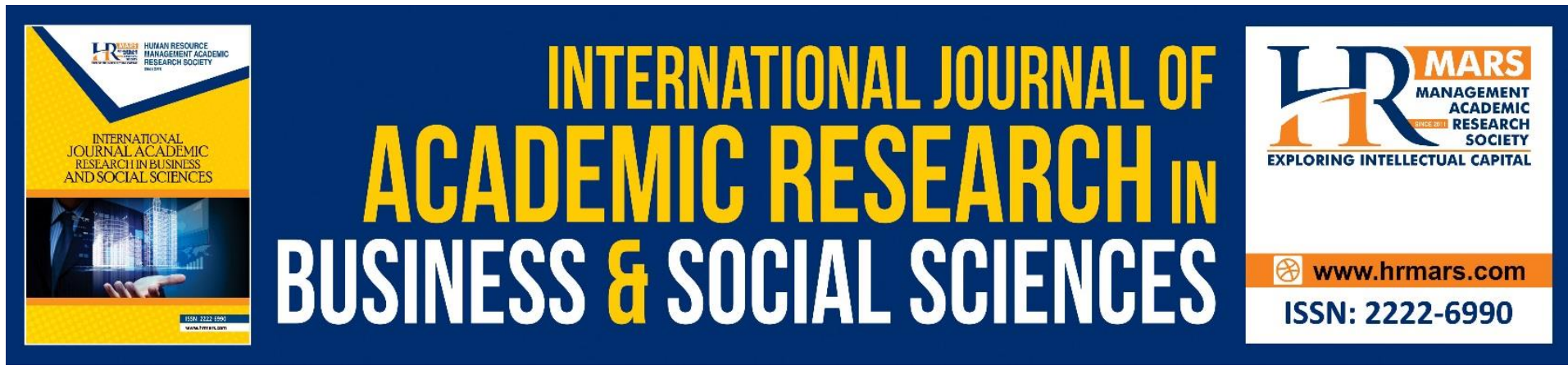

\title{
Stimulating Interactive Apps in Conserving Batik Block Pattern
}

\author{
Norfadilah Kamaruddin ${ }^{1}$, Mohammad Shahir Ab Satar², Hafizah \\ Rosli $^{3}$ \\ ${ }^{1,2}$ Creative Visual Exchange Group (CREATe), Faculty of Art \& Design, UniversityTeknologi MARA \\ 40450 Shah Alam, Malaysia, ${ }^{3}$ Faculty of Film, Teater and Animation, UniversityTeknologi \\ MARA Puncak Perdana, 42300, Malaysia
}

\begin{abstract}
Batik is a Malaysian culture where the motif and pattern represent our identity and cultural heritage. People prefer to dress elegantly and simply in contemporary society. Additionally, the current batik pattern lacks a robust Malaysian identity. The traditional element also struggles to develop a local identity due to the lack of a descriptive document describing the Malaysian design. This research aims to identify traditional Malaysian batik patterns and develop an interactive application that will aid in the preservation of Malaysian culture and heritage. This study collected data through a review of contextual documents, in-depth interviews, and online survey questionnaires by establishing that Malaysian batik contains numerous patterns that all Malaysians must preserve as part of the country's heritage. Our finding shows that the proposed batik apps have the potential to increase Malaysians' awareness of batik patterns while also contributing to the preservation of culture and heritage value. Individuals can use the app to search for information about batik easily. Furthermore, for the Jabatan Warisan Negara, which is part of the Ministry of Tourism Malaysia, the app will act as a medium for promoting one of Malaysia's cultural and heritage treasures, Batik design.
\end{abstract}

Keywords: Batik Block, Pattern, Interactive Apps

\section{Introduction}

Batik is one of Malaysia's cultures, which its motif and pattern symbolize a representation of our identity and cultural heritage. In contemporary society, people prefer to dress elegantly and simply. There is no need for the highly embellished pattern associated with batik clothing. As a result, to stay current, Batik's pattern has undergone numerous changes. As a result, the pattern is quite abstract and lacks Malaysian identity.

Nevertheless, with a constant change of trends, the local batik pattern representing less and less of Malaysian culture and identity (Poon, 2017). Moreover, the current batik pattern does not contain a robust Malaysian identity further does not have a strong identity and traditional element (Kari et al., 2018). Hence, in this era of modernization, Malaysia is still struggling to develop a local design identity as no specific word can describe the designs originating from 
Malaysia (Ahmad et al., 2015). Thus, this research aims to identify the traditional Malaysian batik pattern and further propose an interactive application that can help preserve Malaysian culture and heritage.

This research provides info about Malaysian traditional batik patterns and helps preserve the knowledge of traditional batik patterns. By proposing an app as an interactive medium in learning batik patterns, it can be referred to by many batik industries when they are creating a new pattern. Furthermore, this research can empowering batik artisans to increase the quality production of batik patterns.

\section{Literature Review}

The word 'Batik' is derived from 'ambatik', which means 'a cloth with tiny dots'. Batik may also have originated from the Javanese word 'tritik', which describes a resist process for dying where the pattern is reserved on the textile by tying and sewing (Steelyana, 2012). From a previous research study, Batik was established as a form of artistic expression with unique features that could become an identity or may become a cultural identity for either the region or the nation (Syakir et al., 2017). Accordingly, fabric pattern designs commonly represent the tradition and culture of local communities (Puarungroj \& Boonsirisumpun, 2019). This proves the importance of understanding patterns used on fabric is important to preserve the cultural heritage and know better.

According to Puarungroj \& Boonsirisumpun (2019), pattern design commonly represents local communities' traditions and culture. This is presented by example Indonesians place more importance on batik designs which reflect their identity. Indeed, Indonesian patterns such as lotus flower, Parang Rusak, and Garuda bird known as Batik Kraton (And \& Nagar, 2009) were established across the world to illuminate their culture and heritage identity.

In Malaysia, one popular pattern in the fabric is the floral pattern, ranging from leaf, branches, petal, and ivy. According to Purba \& Kusuma (2017), the root pattern is very rare and difficult to find in batik pattern design. By referring to the batik pattern in Malaysia, most of the motifs have undergone a transformation, whereby the batik producers are no longer used designs that reflect traditional styles and identities (Kari et al., 2018). To establish batik as a modern product, manufacturers must infuse the batik block with a Malaysian identity (Haziyah Hussin, 2006).

The literature established the importance of understanding the pattern and preserving the culture and heritage. Therefore, the Malaysian Batik industry is affected by marketing strategy, competition with the modern clothing industries, and less creativity and innovation in producing attractive and exclusive designs (Lias et al., 2020). Based on this issue, this study takes the batik pattern as a sample of the study and looks at the platform's potential to promote the pattern in today's demand.

\section{Research Methodology}

This study is using contextual documents review, in-depth interviews, and online survey questionnaires. The primary data is gathered from in-depth interviews and online surveys, while secondary data is from contextual documents review. For a contextual documents review, the research begins with collecting related journals. Twenty journals were reviewed 
using thematic analysis procedures. The outcomes of the review were established in categories and themes style. The participants for the in-depth interview session are people from the batik industry in Terengganu, Malaysia. This includes the batik expert, who is highly knowledgeable about batik patterns and can provide the necessary information for the research. All interviewees were asked open-ended questions about batik patterns and the originality of batik elements. The online survey questionnaires were used to ascertain public preferences for interactive applications aimed at promoting batik patterns. Google Form is being used to host the online survey questionnaires distributed via email and social media.

\section{Findings \& Discussions}

Three in-depth interviews were conducted online to gather necessary information and knowledge before deciding on a potential medium for promoting batik patterns. The interview session revealed additional information about batik production and pattern design. The majority of participants explain and justify their batik patterns. Additionally, all participants agreed that it was difficult for them to stay current on design trends due to a lack of sources. The study's findings can be summarized as follows:

1. There are mainly three batik production techniques established in Malaysia: canting, block-printing, and silk screening.

2. The batik artist's satisfaction is in a color language when they are producing batik patterns. Thus the trend of the batik artist decorate the fabric today is in whatever way they want using whatever pattern they like.

3. Various materials are used in the process of batik. Thus this is influencing the various style for batik patterns. Here is an example of a batik pattern in Malaysia (Figure 1).
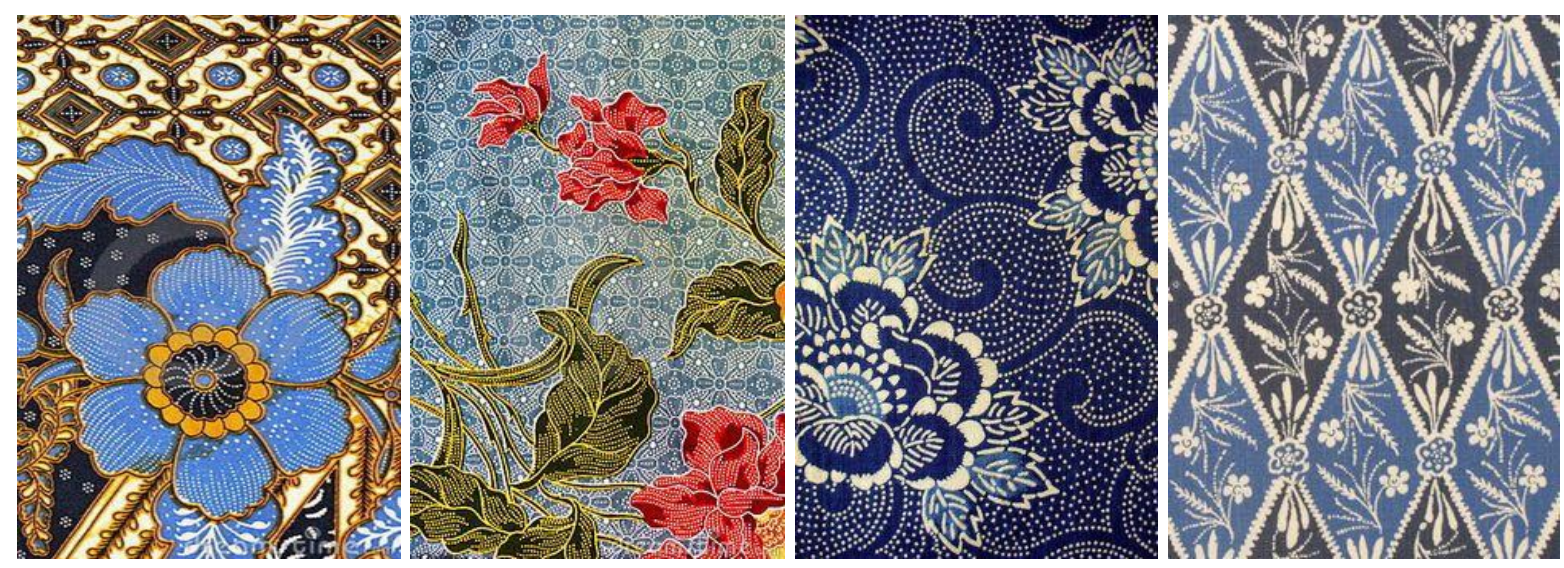

Figure 1: Example of Malaysian batik pattern

Two in-depth interviews were also conducted with the Graphic Designer. The purpose is mainly focused on the design aspects of the potential medium that can promote the Malaysian batik pattern. The main point of discussion is on the element of design, the color, typeface used, the layout, and discussing several features that could be used further. Both the designers provided insight into the interfaces of the potential media promoting and how each element should give smooth and clear user experiences.

On the other hand, the online survey was conducted with the public. The main purpose of the survey is to inquire the public about their knowledge of the batik pattern. Within a week, 100 
participants were responded to the survey. The survey's result shows that only $14 \%$ of the total respondents know about batik patterns. Therefore $40 \%$ of them claimed that they were never interested in the pattern. Most of the respondents were suggested having an interactive app rather than a website or e-book. The data survey also revealed that most of the respondents required tutorial video as one of the features in the app.

The data obtained from both methods were analyzed and then added to the development of the apps. Most of the placement and layout from the apps refers to the data collected from the interview and survey.

\section{Prototype Development}

The main purpose of batik's apps is to educate people about batik patterns, preserving knowledge about batik patterns, and further creating a community for batik entrepreneurs. Based on the data gathered from the in-depth interview with the batik experts and online survey with the public, there are three basic steps in developing a prototype of the batik's apps. The first step is rough ideation followed by comprehensive design and final prototype.

The interface layout is prepared roughly through black and white looks (Figure 2). In particular, at these stages, it is more on the button placement and setting pages.

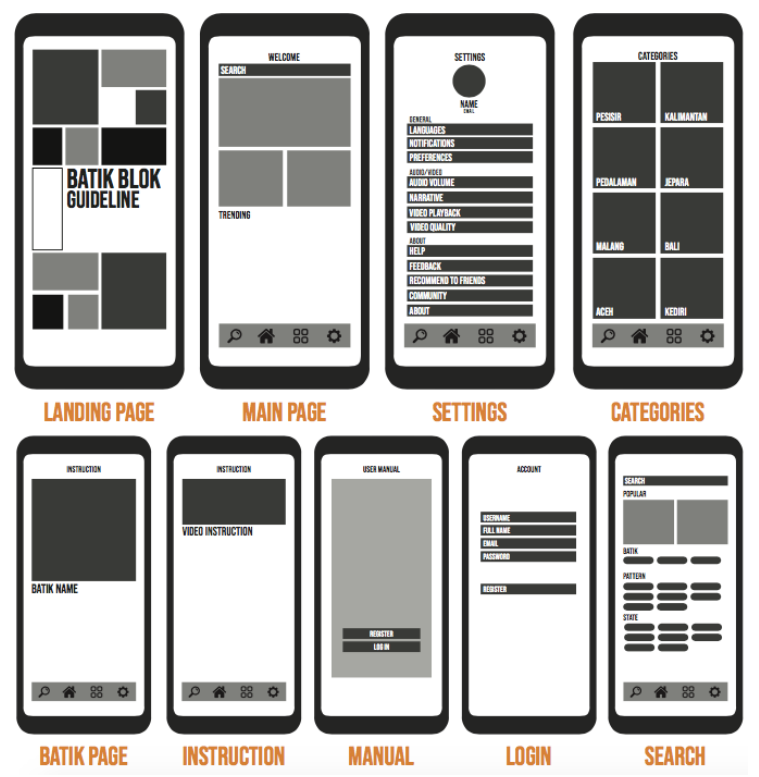

Figure 2: Rough interface layout

The second stage of the development has been focusing more on the comprehensive design (Figure 3). It includes adjusting font types, adding appropriate colors and features, and creating a more stylized shape for the interface. This stage aims to make the interface more visually attractive. All the ideas and references for the design are taken from data analysis of the survey and interview. 


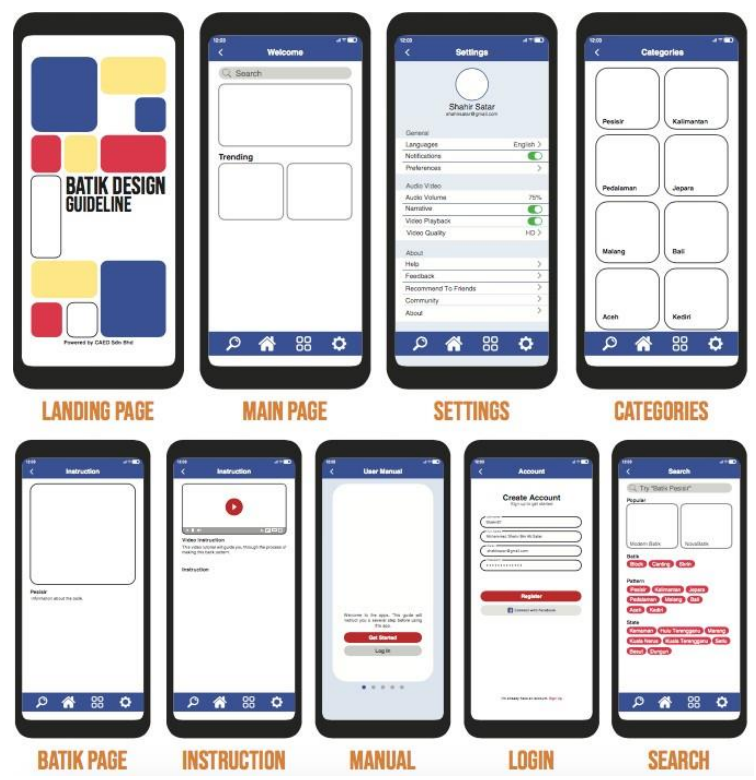

Figure 3: Comprehensive Design

The final phase for the design development of Batik's apps is the final design for the prototype (Figure 3). This stage involved inserting the detailed data needed for the apps to function, such as the image in the apps, inserting the button's name under the icon, and the information about the batik pattern.
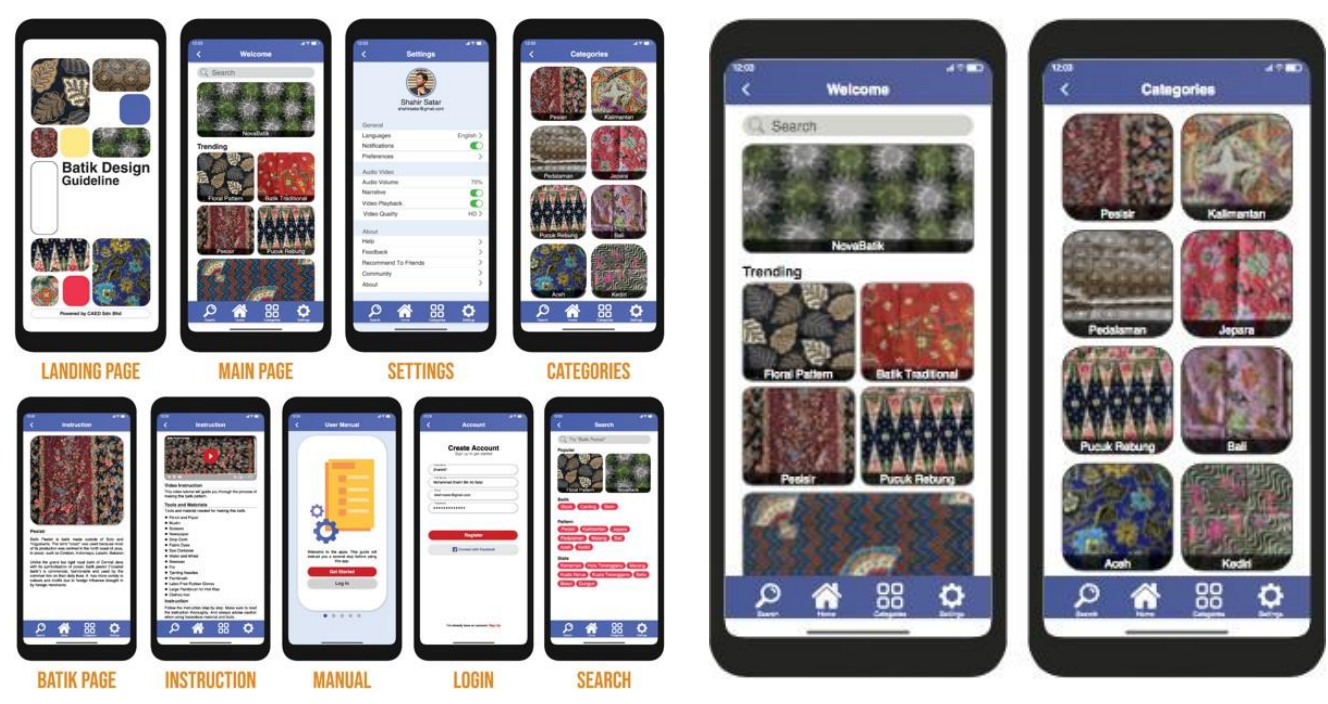

Figure 3: The final looks

These batik's apps are designed to be user-friendly to be accessible to many age ranges, including for first-timers. Few features were included in the apps such as it can search up any keyword that is available in the apps. The apps also contain many categories about batik types and patterns where users can browse them to learn about each of the patterns. Furthermore, for each pattern, there will be a video tutorial on each pattern. Users can change the main interface up to their preferences, users can change the color, font size, audio volume, background theme, and feedback about the apps. This app is also can be connecting to Facebook, users can log in and connect with many people interested in batik patterns. For those who are familiar with the application, there is a user manual at the startup. 


\section{Conclusion}

This study was revealed three interesting findings including three batik production techniques established in Malaysia, the trend of the batik artist decorate the fabric today is based on whatever way they want and style for batik patterns are influenced by the process. By proposing a user-friendly batik app which accessible to various age groups, including first timers, the batik apps proposed is the possible way to increasing the awareness level among Malaysians towards batik patterns and further preserving culture and heritage value. The apps that connected to social media also contains all the necessary information about batik production techniques, artists' justification, and explanations established in Malaysia. In conclusion, based on the main findings mention above, this research has met its purpose which is identifying the traditional Malaysian batik pattern and further propose an interactive application that can help in preserving Malaysia's culture and heritage. Furthermore, this research suggests that Jabatan Warisan Negara, under the Ministry of Tourism Malaysia, should use the app as a promotional tool to promote Malaysia's cultural and heritage and batik design.

\section{References}

Ahmad, M. F., Hasan, Z., \& Romli, Z. (2015). Furniture Design Identity: Implementation of National Identity into Office Chair Design. International Colloquium of Art and Design Education Research (I-CADER 2014), 367-372. https://doi.org/10.1007/978-981-287332-3_38

And, A., \& Nagar, V. (2009). A comparative study of traditional and modern batik. http://researchjournal.co.in/upload/assignments/4_390-391.pdf

Haziyah Hussin. (2006). Motif alam dalam batik dan songket Melayu. Dewan Bahasa Dan Pustaka.

Kari, R., Samin, A., \& Legino, R. (2018). Sustainability of Traditional Motifs in Malaysian Batik Block. International Journal of INTI, 22. https://jadinti.uitm.edu.my/images/Volume22_Dec2018/Rabia83.pdf

Lias, H., Ismail, A. R., \& Hamid, H. A. (2020). Malaysia Textile Craft Industry: Innovation Inspired by Bamboo for Batik Block Contemporary Design. IOP Conference Series: Earth and Environmental Science, 549, 012087. https://doi.org/10.1088/17551315/549/1/012087

Purba, D., \& Kusuma. (2017). FIBROUS ROOT MODEL IN BATIK PATTERN GENERATION. Journal of Theoretical and Applied Information Technology, 31(14). http://www.jatit.org/volumes/Vol95No14/11Vol95No14.pdf

Puarungroj, W., \& Boonsirisumpun, N. (2019). Recognizing Hand-Woven Fabric Pattern Designs Based on Deep Learning. Advances in Intelligent Systems and Computing, 325336. https://doi.org/10.1007/978-981-13-6861-5_28

Steelyana, E. (2012). Batik, A Beautiful Cultural Heritage that Preserves Culture and Supporteconomic Development in Indonesia. Binus Business Review, 3(1), 116. https://doi.org/10.21512/bbr.v3i1.1288

Syakir, S., Soesanto, S., \& Tohir, M. (2017). LOCALITY IN CONSTRUCTING CULTURAL IDENTITY (A REVIEW ON SEMARANG BATIK ART). The Journal of Educational Development, 5(2), 198-209. https://doi.org/10.15294/jed.v5i2.14378

Poon, T. F. S. (2017). The Journey to Revival: Thriving Revolutionary Batik Design and Its Potential in Contemporary Lifestyle and Fashion. International Journal of History and Cultural Studies, 3(1). https://doi.org/10.20431/2454-7654.0301006 